\title{
Safety of Non-stented Pancreaticojejunostomy in Pancreaticoduodenectomy for Patients with Soft Pancreas
}

\author{
TERUYUKI USUBA, TAKEYUKI MISAWA, RYUSUKE ITO, KAZUHIKO YOSHIDA, \\ NOBUYOSHI HANYU and KATSUHIKO YANAGA
}

Department of Surgery, The Jikei University School of Medicine, Tokyo, Japan

\begin{abstract}
Background/Aim: It has been reported that pancreatic duct stenting for pancreaticojejunostomy in pancreaticoduodenectomy prevents postoperative pancreatic fistula. However, some reports describe severe complications associated with pancreatic duct stenting; it is controversial whether pancreatic duct stent should be used for pancreaticojejunal anastomosis in pancreaticoduodenectomy. The aim of this study was to compare the incidence of pancreatic fistula between non-stented, externally stented, and internally stented pancreaticojejunostomy in pancreaticoduodenectomy for patients with soft pancreas. Patients and Methods: Ninety-eight patients undergoing pancreaticoduodenectomy with soft pancreas were divided into three groups: a non-stented group $(n=14)$, an externally-stented group $(n=56)$, and an internallystented group $(n=28)$, then clinical outcomes were compared. Results: The frequency of clinically relevant postoperative pancreatic fistula (grade B or C) was $14 \%$ in the non-stented group, $36 \%$ in the externally-stented group, and $39 \%$ in the internally-stented group, respectively $(p=0.19)$. The morbidity and mortality rates were also comparable between the three groups ( $p=0.17$ and $p=0.88$, respectively). Conclusion: Since pancreatic duct stenting in pancreaticojejunal anastomosis for patients with soft pancreas did not reduce pancreatic fistula after pancreaticoduodenectomy, non-stented pancreaticojejunostomy for soft pancreas seems safe.
\end{abstract}

Pancreaticoduodenectomy (PD) is a standard treatment for patients with pancreatic head and periampullary tumors. Recently, the mortality rate after PD has decreased to less than $5 \%$ because of advances in surgical techniques and appropriate perioperative management (1-3). However, the morbidity rate

Corespondence to: Teruyuki Usuba, Department of Surgery, Katsushika Medical Center The Jikei University School of Medicine, Aoto 6-41-2, Katsushika-ku, Tokyo 125-8506, Japan. Tel: +81 336032111, Fax: +81 338389945, e-mail: usuba@jikei.ac.jp

Key Words: Non-stented pancreaticojejunostomy, pancreaticoduodenectomy, soft pancreas. remains high, ranging from $30-50 \%$, of which postoperative pancreatic fistula (POPF) is the most frequent life-threating complication, with an incidence of $10-30 \%$ (3-7). It has been reported that pancreatic duct stenting for pancreaticojejunostomy in PD prevents POPF, and therefore pancreatic duct stent has been used in many institutions $(8,9)$. On the other hand, some reports describe severe complications associated with pancreatic duct stenting, such as acute pancreatitis due to occlusion or bending of the stent, anastomotic leakage or stenosis after iatrogenic injury caused by removal of an external stent (ES), and obstructive jaundice or cholangitis caused by migration of an internal stent (IS) (10-12). Several randomized control studies have controversially reported both efficacy and non-efficacy of pancreatic duct stenting for the prevention of POPF (13-16). There are some reports comparing the efficacy of external and internal stents, finding them to have equivalent outcome $(10,17)$. Recent meta-analyses on stenting versus non-stenting are contradictory (18-23). Therefore, it is still controversial whether a pancreatic duct stent should be used for pancreaticojejunal anastomosis in PD.

In pancreatic surgery, a soft pancreas is known to be a significant risk factor for POPF when compared to a hard pancreas $(24,25)$. Since soft pancreas is vulnerable to ischemia and actively produces exocrine secretions, bleeding, autolysis, necrosis, or pancreatic fistula can easily occur after surgical intervention (26). Therefore, it is important to treat patients with soft pancreas carefully. The aim of this study was to compare the incidence of POPF between non-stented, externally-stented, and internally-stented pancreaticojejunostomy for patients with soft pancreas.

\section{Patients and Methods}

Between January 2000 and December 2014, PD was performed for 185 patients at the Katsushika Medical Center, The Jikei University School of Medicine, or Machida Municipal Hospital, Japan. Among them, 98 patients with soft pancreas were retrospectively analyzed in this study. Soft pancreas was defined by the presence of a nondilated main pancreatic duct (less than $3 \mathrm{~mm}$ ) and intraoperative findings of soft pancreatic texture without fibrosis. The patients were divided into three groups: non-stented group (NS, n=14), ES 
group $(n=56)$, and IS group $(n=28)$. Preoperative parameters, clinical data, details of surgical procedures, and postoperative outcomes were compared between the three groups.

Surgical technique. Conventional, pylorus-preserving or subtotal stomach-preserving PD was performed according to each surgeon's preference. Reconstruction in all PD consisted of an end-to-side pancreaticojejunostomy, an end-to-side hepaticojejunostomy, and gastrojejunostomy or duodenojejunostomy using the first jejunal loop, according to Child's procedure (27). Duct-to-mucosa anastomosis of pancreaticojejunostomy was performed with eight interrupted polydioxanone sutures (5-0 PDS-II ${ }^{\circledR}$; Ethicon, Cincinnati, OH, USA), followed by a pancreatic parenchymaljejunal seromuscular anastomosis by polypropylene sutures (PROLENE ${ }^{\circledR}$; Ethicon).

The decision on whether to use a pancreatic duct stent was also left at the surgeon's discretion. Bile-duct stent in hepaticojejunostomy and feeding tube in the jejunum were not routinely used. The pancreatic duct stent was a 5- to 6-Fr polyvinyl catheter (MD-41515 pancreatic duct tube; Sumitomo Bakelite, Tokyo, Japan) with multiple side holes. As an ES method, the tip of the pancreatic duct stent was inserted through the pancreaticojejunal anastomosis into the main pancreatic duct, then the other end of the tube was extracted through a stab incision both in the jejunal and abdominal wall. As an IS method, the tip of pancreatic duct stent, $5-\mathrm{cm}$ in length, was positioned one half in the main pancreatic duct and the other half in the jejunal lumen. The decision on whether to use fibrin glue for preventing leakage around the anastomotic site was also left at the surgeon's discretion. Surgical drains were placed in the sites of the pancreaticojejunal and hepaticojejunal anastomoses in all patients.

Perioperative management. All patients were given preoperative and postoperative prophylactic antibiotics for at least 3 days after the operation. Postoperative prophylactic octreotide acetate was not administered, and oral intake was routinely started 3 to 7 days after surgery when there was no evidence of intra-abdominal complications. Amylase levels in serum and drainage fluid were measured on days 1, 3 and 5 after surgery. Intra-abdominal drains were removed as soon as possible, between postoperative day 4 and 7, after confirming the absence of clinically relevant (CR) POPF. ES were removed around 3 to 4 weeks postoperatively if there was no evidence of CR-POPF.

Definitions. CR-POPF was defined as grade B and C according to the International Study Group on Pancreatic Fistula grading system (7). Complications were classified in accordance with Clavien's classification (28).

Statistical analysis. Continuous data are expressed as the mean \pm SD. Comparisons of continuous variables between the three groups were performed using the Kruskal-Wallis test. A $p$-value of less than 0.05 was judged to be statistically significant.

\section{Results}

Patient characteristics and clinical diagnoses of the three groups are summarized in Table I. There were significant differences in age and co-morbidity between the three groups. The patients of ES were younger than those of the other groups $(p=0.002)$, and the co-morbidity rate of ES was less
Table I. Patient characteristics and clinical diagnosis.

\begin{tabular}{lcccc}
\hline Preoperative parameter & $\begin{array}{c}\text { No } \\
\text { stent } \\
(\mathrm{n}=14)\end{array}$ & $\begin{array}{c}\text { External } \\
\text { stent } \\
(\mathrm{n}=56)\end{array}$ & $\begin{array}{c}\text { Internal } \\
\text { stent } \\
(\mathrm{n}=28)\end{array}$ & $p$-Value \\
\hline Age (years) & $72.7 \pm 8.4$ & $66.9 \pm 6.8$ & $73.1 \pm 7.1$ & 0.002 \\
Sex $($ male/female $)$ & $11 / 3$. & $38 / 18$. & $22 / 6$. & 0.502 \\
BMI $\left(\mathrm{kg} / \mathrm{m}^{2}\right)$ & $23.1 \pm 2.6$ & $22.4 \pm 3.2$ & $22.8 \pm 3.5$ & 0.324 \\
Co-morbidity & $12(86 \%)$ & $27(48 \%)$ & $20(71 \%)$ & 0.013 \\
Hypertention & 9 & 16 & 12 & \\
Diabetes mellitus & 5 & 10 & 12 & \\
Cardiac disease & 2 & 0 & 1 & \\
Pulmonary disease & 0 & 0 & 3 & \\
Cerebral disease & 1 & 1 & 2 & \\
Diagnosis & & & & 0.642 \\
Malignant diseases & $11(79 \%)$ & $47(84 \%)$ & $25(89 \%)$ & \\
Pancreatic carcinoma & 1 & 5 & 1 & \\
Cholangiocarcinoma & 6 & 14 & 14 & \\
Ampullary carcinoma & 2 & 20 & 8 & \\
IPMN & 4 & 8 & 2 & \\
Other & 1 & 9 & 3 & \\
\hline
\end{tabular}

BMI: Body mass index; IPMN: intraductal papillary mucinous neoplasm. Data are the mean $\pm \mathrm{SD}$, or number $(\%)$.

Table II. Intraoperative variables for patients undergoing pancreaticoduodenectomy $(P D)$.

\begin{tabular}{lcccc}
\hline & $\begin{array}{c}\text { No } \\
\text { stent } \\
(\mathrm{n}=14)\end{array}$ & $\begin{array}{c}\text { External } \\
\text { stent } \\
(\mathrm{n}=56)\end{array}$ & $\begin{array}{c}\text { Internal } \\
\text { stent } \\
(\mathrm{n}=28)\end{array}$ & $p$-Value \\
\hline Procedure & & & & $<0.001$ \\
$\quad$ PD & 1 & 35 & 1 & \\
$\quad$ PPPD & 12 & 19 & 19 & \\
$\quad$ SSPPD & 1 & 8 & 8 & \\
Operative time (min) & $397 \pm 80$ & $470 \pm 119$ & $397 \pm 60$ & $<0.001$ \\
Blood loss (ml) & $1670 \pm 739$ & $1764 \pm 1470$ & $1307 \pm 1103$ & 0.149 \\
Blood transfusion & $5(36 \%)$ & $24(43 \%)$ & $12(43 \%)$ & 0.882 \\
Use of fibrin glue & $13(93 \%)$ & $29(52 \%)$ & $22(79 \%)$ & $<0.001$ \\
\hline
\end{tabular}

PPPD: Pyrolus-preserving PD; SSPPD: subtotal stomach-preserving PD. Data are the mean $\pm \mathrm{SD}$, or number $(\%)$.

than those of the other groups $(p=0.013)$. The malignancy rates of primary disease were comparable between the three groups $(p=0.642)$. There were statistically significant differences between the three groups in procedure, operative time, and the use of fibrin glue (Table II). The number of conventional PDs in patients of the ES group was greater than those of the other two groups $(p<0.001)$. The operative time for ES was longer than those of the other groups $(p<0.001)$. The use of fibrin glue in patients of the NS group was more frequent than those of the other groups $(p<0.001)$. There were no significant differences between the three groups in morbidity and mortality (Table III). 
Table III. Postoperative outcomes of patients who underwent pancreaticoduodenectomy.

\begin{tabular}{lcccc}
\hline & $\begin{array}{c}\text { No } \\
\text { stent } \\
(\mathrm{n}=14)\end{array}$ & $\begin{array}{c}\text { External } \\
\text { stent } \\
(\mathrm{n}=56)\end{array}$ & $\begin{array}{c}\text { Internal } \\
\text { stent } \\
(\mathrm{n}=28)\end{array}$ & $p$-Value \\
\hline $\begin{array}{l}\text { Complication } \\
\begin{array}{l}\text { Clavien-Dindo } \geq 3) \\
\text { Pancreatic fistula }\end{array}\end{array}$ & $2(14 \%)$ & $23(41 \%)$ & $10(36 \%)$ & 0.174 \\
$\quad 5(36 \%)$ & $28(50 \%)$ & $14(50 \%)$ & 0.338 \\
$\begin{array}{l}\text { Grade A } \\
\text { Grade B }\end{array}$ & $3(21 \%)$ & $8(14 \%)$ & $3(11 \%)$ & 0.5 \\
Grade C & $2(14 \%)$ & $14(25 \%)$ & $9(32 \%)$ & 0.422 \\
$\quad$ Grade B+C (CR-POPF) $)$ & $2(14 \%)$ & $6(11 \%)$ & $2(7 \%)$ & 0.413 \\
Mortality & $1(7 \%)$ & $3(5 \%)$ & $11(39 \%)$ & 0.195 \\
Reoperation & $1(7 \%)$ & $6(11 \%)$ & $2(7 \%)$ & 0.877 \\
Postoperative & $21.3 \pm 12.3$ & $33.5 \pm 22.9$ & $31.9 \pm 28.5$ & 0.054 \\
hospital stay (days) & & & & \\
\hline
\end{tabular}

CR-POPF: Clinically relevant postoperative pancreatic fistula. Data are the mean \pm SD number $(\%)$.

The rate of overall POPF was 36\% in NS, 50\% in ES and $50 \%$ in IS, respectively $(p=0.338)$. The rate of CR-POPF was $14 \%$ in NS, $36 \%$ in ES and $39 \%$ in IS, respectively $(p=0.195)$. The overall morbidity (Clavien's classification 3 or more) rate was $14 \%$ in NS, $41 \%$ in ES and $36 \%$ in IS $(p=0.174)$. Although surgical or radiological treatment regarding postoperative complications was required in one patient $(7 \%)$ in the NS group, six patients $(18 \%)$ in the ES group, and two patients (8\%) in the IS group, there was no statistically significant difference $(p=0.832$ ).

Hospital mortality rate was $7 \%$ in the NS, $5 \%$ in the ES, and $4 \%$ in the IS group without a statistically significant difference $(p=0.877)$. One patient died 49 days after surgery in the NS group due to progression of malignant lymphoma of the duodenum. The reasons for three deaths in the ES group were intra-abdominal hemorrhage following CR-POPF in two and deterioration of co-morbidity with chronic renal failure in one patient, respectively. These patients died 33, 31, and 70 days after surgery, respectively. Another patient in the IS group died 58 days after surgery due to intra-abdominal hemorrhage following CR-POPF. Therefore, all three deaths $(3.1 \%)$ due to POPF were in the stented groups, and none in the NS group. Postoperative hospital stay was comparable $(p=0.054)$, and postoperative hospital stay of the NS group tended to be shorter than that for the other groups. Ninetyeight PDs were performed by a total of 23 surgeons, eight of which were senior and 15 of which were junior surgeons. The clinical outcomes when compared by surgeon are shown in Table IV. The number of NS cases operated on by senior surgeons was more than those of ES and IS $(p<0.001)$. The operative time performed by junior surgeons was longer than that of senior surgeons $(p=0.003)$. The CR-POPF rate was
Table IV. Clinical outcomes compared by surgeon type.

\begin{tabular}{lccc}
\hline Surgeon & $\begin{array}{c}\text { Senior } \\
(\mathrm{n}=39)\end{array}$ & $\begin{array}{c}\text { Junior } \\
(\mathrm{n}=59)\end{array}$ & $p$-Value \\
\hline No stent & 13 & 1 & $<0.001$ \\
External stent & 19 & 37 & 0.171 \\
Internal stent & 7 & 21 & 0.058 \\
Operative time (min) & $402 \pm 95$ & $452 \pm 94$ & 0.003 \\
Blood loss (ml) & $1484 \pm 1374$ & $1601 \pm 1185$ & 0.535 \\
CR-POPF & 13 & 20 & 0.954 \\
Mortality & 5 & 0 & 0.005 \\
\hline
\end{tabular}

CR-POPF: Clinically-relevant postoperative pancreatic fistula. Data are the mean \pm SD number (\%).

Table V. Summary of recent meta-analyses.

\begin{tabular}{lccccc}
\hline Author (Ref) & \multirow{2}{*}{ Year } & No. of cases & \multicolumn{2}{c}{ PO PF } & \multirow{2}{*}{ p-value } \\
\cline { 3 - 5 } & & & NS & S & \\
\hline Xiong et al. (19) & 2012 & 1.726 & $28 \%$ & $22 \%$ & 0.13 \\
Markar et al. (20) & 2012 & 732 & $26 \%$ & $20 \%$ & 0.13 \\
Wang et al. (21) & 2013 & 793 & $22 \%$ & $29 \%$ & 0.02 \\
Hong et al. (22) & 2013 & 416 & $33 \%$ & $19 \%$ & 0.001 \\
Zhou et al. (18) & 2013 & 724 & $11 \%$ & $14 \%$ & 0.31 \\
Patel et al. (23) & 2014 & 416 & $38 \%$ & $19 \%$ & 0.0001 \\
\hline
\end{tabular}

POPF: Postoperative pancreatic fistula, NS: no-stented group, SG: stent group.

comparable between senior and junior surgeons $(p=0.954)$. Mortality rate of those treated by senior surgeons was higher than for those treated by junior surgeons $(p=0.005)$.

\section{Discussion}

POPF is a common and life-threating complication after PD (13-17). Various techniques have been advocated and evaluated to reduce POPF by many surgeons. Influenced by the reports in which pancreatic duct stent for pancreaticojejunostomy in PD prevents POPF $(8,9)$, pancreatic duct stent is routinely used in many Institutions. In six recent meta-analyses, three reports demonstrated that a pancreatic duct stent was useful for preventing POPF (21-23) (Table V). On the other hand, the other three meta-analyses demonstrated that such stenting did not reduce POPF (18-20). Moreover, some prospective randomized trials and retrospective studies demonstrated that the POPF rate of NS was equal to that of the stented group (13, $15,29)$. Winter et al. reported that the POPF rate was $11.3 \%$ in the stented group and $7.6 \%$ in the NS group $(p=0.10)(13)$, Pessaux et al. reported that the CR-POPF rate was $24.7 \%$ in the ES group and $35.8 \%$ in the NS group $(p=0.13)(15)$, and 
Moriya et al. reported that the CR-POPF rate was $9.6 \%$ in the stented group and $12.5 \%$ in the NS group $(p=0.38)(29)$. On the other hand, Sachs et al. retrospectively evaluated clinical outcomes between NS $(n=385)$ and the stented groups $(n=59)$ and reported that the CR-POPF rates were $11 \%$ and $29 \%$ $(p<0.001)$, respectively (30). They also concluded that the use of pancreatic duct stent does not reduce the incidence of CRPOPF. Imaizumi et al. demonstrated that pancreatic duct stenting was unnecessary if the duct-to-mucosa anastomosis was performed properly (26). Suzuki et al. also insisted there was no need for use of a pancreatic duct stent in pancreaticojejunostomy (31), and we also do not consider that a pancreatic duct stent is necessary for all patients.

Soft pancreas is a risk factor for POPF after PD because a soft pancreas is very vulnerable to ischemia and actively produces exocrine secretion (31). There are some reports with regard to POPF in soft pancreas $(13,16,18,26,29)$ (Table VI). In a meta-analysis, Zhou et al. reported that the POPF rate with soft pancreas was $22.9 \%$ in the stented group as compared to $36.6 \%$ in the NS group ( $p=0.05)(18)$. In a randomized study, Motoi et al. reported that CR-POPF (pancreatic duct $<3 \mathrm{~mm}$ ) was $10 \%$ in the stented group as compared to $40 \%$ in the NS group $(p<0.05)(16)$. On the other hand, there are some reports that the POPF rate for NS with soft pancreas was equivalent to that of stented PD. Winter et al. reported that POPF with soft pancreas was $21.1 \%$ in the stented group and $10.7 \%$ in the NS group ( $p=0.10)$ (13). Imaizumi et al. reported that POPF with soft pancreas was $7.7 \%$ in the stented group and $7.3 \%$ in the NS group, with no significant difference (26). Moriya et al. reported that POPF with soft pancreas was $23.8 \%$ in the IS and $37.8 \%$ in the NS groups $(p=0.20)$. Moreover, they reported that CR-POPF with soft pancreas was $17.7 \%$ in the IS and $24.3 \%$ in the NS groups $(p=0.38)$ (29). Suzuki et al. reported that it was important to maintain the patency of the anastomosis in pancreaticojejunostomy in order to prevent POPF, for which non-stented pancreaticojejunostomy was useful (31). Therefore, it is also controversial whether a pancreatic duct stent should be used for pancreaticojejunal anastomosis in patients with soft pancreas.

In our retrospective study, there were no significant differences in the incidence of POPF and CR-POPF between the three groups. In addition, morbidity and mortality rates were also similar. Clinical outcomes of the stented groups were comparable, and NS pancreticojejunostomy with soft pancreas was acceptable. Based on the current study, it may not be necessary to use a pancreatic duct stent for patients with soft pancreas. However, several biases exist in the current study, such as the age of patients, co-morbidity rate, subtypes of procedure, operative time, and use of fibrin glue. Because most NS pancreaticojejunostomies were performed by senior surgeons and many stented pancreatojejunostomies were performed by junior surgeons, operative time of the stented groups was longer than that of the NS group.
Table VI. Reports on postoperative pancreatic fistula (POPF) for patients with soft pancreas.

\begin{tabular}{lcccc}
\hline \multirow{2}{*}{ Author (Ref) } & Year & \multicolumn{2}{c}{ PO PF } & \multirow{2}{*}{$p$-Value } \\
\cline { 3 - 4 } & & $\mathrm{NS}$ & $\mathrm{S}$ & \\
\hline Imaizumi et al. (26) & 2002 & $7.30 \%$ & $7.70 \%$ & $\mathrm{NS}$ \\
Winter et al. (13) & 2006 & $10.70 \%$ & $21.10 \%$ & 0.1 \\
Motoi et al. (16) & 2012 & $40 \%$ & $10 \%$ & $<0.05$ \\
Moriya et al. (29) & 2012 & $24.30 \%$ & $17.70 \%$ & 0.38 \\
Zhou et al. (18) & 2013 & $37 \%$ & $23 \%$ & 0.05 \\
\hline
\end{tabular}

NS: No-stented group, SG: stent group, ns: no significance.

Moreover, it cannot be evaluated that good outcomes of the NS group were the result of operations by senior surgeons because all cases of mortality were associated with surgery by senior surgeons (as shown in Table IV).

In the current study, we had two complications caused by pancreatic duct stenting: local peritonitis due to accidental removal of stent and cholangitis due to migration of internal stent into the bile duct in one case. Besides, anastomotic leakage in a patient with hard pancreas immediately after removal of an external stent can occur. Furthermore, selfremoval of a stent is a serious concern in elderly patients with delirium. Therefore, we do not consider that a pancreatic duct stent should be used in all patients. In the future, it is necessary to examine what kind of patients with soft pancreas need pancreatic duct stenting in a large-scale prospective study.

\section{Conclusion}

Since pancreatic duct stenting for soft pancreas did not reduce POPF after PD in the current study, we conclude that non-stented pancreaticojejunostomy for patients with a soft pancreas seems safe.

\section{Disclosure}

The Authors declare that they have no conflict of interest in regard to this study.

\section{References}

1 Yeo CJ, Cameron JL, Sohn TA, Lillemoe KD, Pitt HA, Talamini MA, Hruban RH, Ord SE, Sauter PK, Coleman J, Zahurak ML, Grochow LB and Abrams RA: Six hundred fifty consecutive pancreaticoduodenectomies in the 1990s pathology, complications, and outcomes. Ann Surg 26: 248-257, 1997.

2 Poon RT, Fan ST, Lo CM, Liu CL, Lam CM, Yuen WK, Yeunq $\mathrm{C}$ and Wong J: Pancreaticoduodenectomy with en bloc portal vein resection for pancreatic carcinoma with suspected portal vein involvement. World J Surg 28: 602-608, 2004. 
3 Kimura W, Miyata H, Gotoh M, Hirai I, Kenjo A, Kitagawa Y, Shimada M, Baba H, Tomita N, Nakagoe T, Sugihara K and Mori M: Pancreaticoduodenectomy risk model derived from 8575 cases from a national single-race population (Japanese) using a web-based data entry system: the 30-day and in-hospital mortality rates for pancreaticoduodenectomy. Ann Surg 259: 773-780, 2014 .

4 Gouma DJ, van Greenen RC, van Gulik TM, de Haan RJ, de Wit LT, Busch OR and Obertop H: Rates of complications and death after pancreaticoduodenectomy: risk factors and the impact of hospital volume. Ann Surg 232: 786-795, 2000.

5 Bassi C, Falconi M, Salvia R, Mascetta G, Molinari E and Pederzoli P: Management of complications after pancreaticoduodenectomy in a high volume center: results on 150 consecutive patients/with invited commentary. Dig Surg 18: 453-458, 2001.

6 Alexakis N, Halloran C, Raraty M, Ghaneh P, Sutton R and Neoptolemos JP: Current standards of surgery for pancreatic cancer. Br J Surg 91: 1410-1427, 2004.

7 Bassi C, Dervenis C, Butturini G, Fingerhut A, Yeo C, Izbicki J, Neoptolemos J, Sarr M, Traverso W and Buchler M; International Study Group on Pancreatic Fistula Definition: Postoperative pancreatic fistula: an international study group (ISGPF) definition. Surgery 138: 8-13, 2005.

8 Yeo CJ and Cameron JL: Improving results of pancreaticoduodenectomy for pancreatic cancer. World J Surg 23: 907-912, 1999.

9 Okamoto A and Tsuruta K: Fistulation method: simple and safe pancreaticojejunostomy after pancreaticoduodenectomy. Surgery 127: 433-438, 2000.

10 Ohwada S, Tanahashi Y, Ogawa T, Kawate S, Hamada K, Tago KI, Yamada T and Morishita Y: In situ vs. ex situ pancreatic duct stents of duct-to-mucosa pancreaticojejunostomy after pancreaticoduodenectomy with billroth I-type reconstruction. Arch Surg 137: 1289-1293, 2002

11 Imaizumi T, Hatori T, Tobita K, Fukuda A, Takasaki K and Makuuchi H: Pancreaticojejunostomy using duct-to-mucosa anastomosis without a stenting tube. J Hepatobiliary Pancreat Surg 13: 194-201, 2006.

12 Rezvani M, O'Moore PV and Pezzi CM: Late pancreaticojejunostomy stent migration and hepatic abscess after Whipple procedure. J Surg Educ 64: 220-223, 2007.

13 Winter JM, Cameron JL, Campbell KA, Chang DC, Riall TS, Schulick RD, Choti MA, Coleman J, Hodgin MB, Sauter PK, Sonnenday CJ, Wolfgang CL, Marohn MR and Yeo CJ: Does pancreatic duct stenting decrease the rate of pancreatic fistula following pancreaticoduodenectomy? Results of a prospective randomized trial. J Gastrointest Surg 10: 1280-1290, 2006.

14 Poon RT, Fan ST, Lo CM, Ng KK, Yuen WK, Yeung C and Wong J: External drainage of pancreatic duct with a stent to reduce leakage rate of pancreaticojejunostomy after pancreaticoduodenectomy: a prospective randomized trial. Ann Surg 246: 425-435, 2007.

15 Pessaux P, Sauvanet A, Mariette C, Paye F, Muscari F, Cunha AS, Sastre B and Arnaud JP; Fédération de Recherche en Chirurgie (French): External pancreatic duct stent decease pancreatic fistula rate after pancreaticoduodenectomy: prospective multicenter randomized trial. Ann Surg 253: 879-885, 2011.

16 Motoi F, Egawa S, Rikiyama T, Katayose Y and Unno M: Randomized clinical trial of external stent drainage of the pancreatic duct to reduce postoperative pancreatic fistula after pancreaticojejunostomy. Br J Surg 99: 524-531, 2012.
17 Kamoda Y, Fujino Y, Matsumoto I, Shinzeki M, Sakai T and Kuroda Y: Usefulness of performing a pancreaticojejunostomy with an internal stent after a pancreatoduodenectomy. Surg Today 38: 524-528, 2008.

18 Zhou Y, Zhou Q, Li Z and Chen R: Internal pancreatic duct does not decrease pancreatic fistula rate after pancreatic resection: a meta-analysis. Am J Surg 205: 718-725, 2013.

19 Xiong JJ, Altaf K, Mukherjee R, Huang W, Hu WM, Li A, Ke NW and Liu XB: Systematic review and meta-analysis of outcomes after intraoperative pancreatic duct stent placement during pancreaticoduodenectomy. Br J Surg 99: 1050-1061, 2012.

20 Markar SR, Vyas S, Karthikesalingam A, Imber C and Malago M: The impact of pancreatic duct drainage following pancreaticojejunostomy on clinical outcome. J Gastrointest Surg 16: 1610-1617, 2012.

21 Wang Q, He XR, Tian JH and Yang KH: Pancreatic duct stents at pancreaticoduodenectomy: a meta-analysis. Dig Surg 30: 415424, 2013.

22 Hong S, Wang H, Yang S and Yang K: External stent versus no stent for pancreaticojejunostomy: a meta-analysis of randomized controlled trials. J Gastrointest Surg 17: 1516-1525, 2013.

23 Patel K, Teta A, Sukharamwala P, Thoens J, Szuchmacher M and DeVito P: External pancreatic duct stent reduces pancreatic fistula: a meta-analysis and systematic review. Int J Surg 12: 827-832, 2014

24 Yeo CJ, Sohn TA, Cameron JL, Hruban RH, Lillemoe KD and Pitt HA: Periampullary adenocarcinoma: analysis of 5-year survivors. Ann Surg 227: 821-831, 1998.

25 Kakita A, Yoshida M and Takahashi T: History of pancreaticojejunostomy in pancreaticoduodenectomy: development of a more reliable anastomosis technique. J Hepatobiliary Pancreat Surg 8: 230-237, 2001.

26 Imaizumi T, Harada N, Hatori T, Fukuda A and Takasaki K: Stenting is unnecessary in duct-to-mucosa pancreaticojejunostomy even in the normal pancreas. Pancreatology 2: 116-121, 2002.

27 Child CG: Pancreaticojejunostomy and other problems associated with the surgical management of carcinoma involving the head of the pancreas. Ann Surg 199: 845-855, 1944.

28 Dindo D, Demoartines N and Clavien PA: Classification of surgical complications: a new proposal with evaluation in a cohort of 6336 patients and results of a survey. Ann Surg 240: 205-213, 2004.

29 Moriya T, Clark CJ, Kirihara Y, Kendrick ML, Reid Lombardo KM, Que FG and Farnell MB: Stenting and the rate of pancreatic fistula following pancreaticoduodenectomy. Arch Surg 147: 35-40, 2012.

30 Sachs TE, Pratt WB, Kent TS, Callery MP and Vollmer CM Jr: The pancreaticojejunal anastomotic stent: friend or foe? Surgery 153: 651-662, 2013.

31 Suzuki S, Kaji S, Koike N, Harada N, Tanaka S, Hayashi T, Suzuki M and Hanyu F: Pancreaticojejunostomy of duct to mucosa anastomosis can be performed more safely without than with a stenting tube. Am J Surg 198: 51-54, 2009.
Received October 14, 2016

Revised November 4, 2016

Accepted November 10, 2016 